\title{
Polychaetes Associated with a Tropical Ocean Outfall: Synthesis of a Biomonitoring Program off $\mathrm{O}^{\prime} \mathrm{ahu}, \mathrm{Hawai}{ }^{\prime}{ }^{1}$
}

\author{
7. H. Bailey-Brock, ${ }^{2,3,4,5}$ B. Paavo, ${ }^{3,4}$ B. M. Barrett, ${ }^{3,4}$ and 7. Dreyer ${ }^{3,4}$
}

\begin{abstract}
A comparison of benthic polychaete communities off the Sand Island Wastewater Outfall was undertaken to recognize organic enrichment indicator species for Hawaiian waters. Primary-treatment sewage is discharged off the south shore of $\mathrm{O}^{\prime} \mathrm{ahu}$ at $70 \mathrm{~m}$ depth. A historical data set spanning $9 \mathrm{yr}$ for seven sites at $70 \mathrm{~m}$ and two recent studies at 20,50 , and $100 \mathrm{~m}$ depths were analyzed. Geochemical data did not support the assumption that the outfall is an important source of organic enrichment in nutrient-poor sandy sediments within oligotrophic tropical waters. Five polychaete species, however, appeared particularly sensitive, positively or negatively, to environmental conditions near the outfall. Neanthes arenaceodentata (Nereididae) and Ophryotrocha adberens (Dorvilleidae) have been dominant at sites within the outfall's zone of initial dilution (ZID). Since $1993, N$. arenaceodentata has virtually disappeared, and O. adberens concurrently became abundant and continued to flourish at ZID sites. Wellknown indicators within the Capitella capitata complex (Capitellidae) were present at ZID and control (far field) sites though their ZID abundance was greater. Two sabellids, Euchone sp. B and Augeneriella dubia were inversely distributed, the smaller Euchone sp. B at far field sites and larger $A$. dubia within ZID stations. The former was most likely restricted to a greater proportion of fine sediment particles at two far field sites. The most abundant and widespread polychaete off O'ahu's south shore was Pionosyllis heterocirrata (Syllidae), which does not seem to represent a sensitive indicator species. Opbryotrocha adberens was the most abundant indicator species within the ZID; P. beterocirrata was the most ubiquitous species at all sites and should always be expected in these sediments. Traditional measurements of numerical abundance, species richness, and diversity $\left(\mathrm{H}^{\prime}\right)$ have not shown a clear distinction between ZID and far field sites in annual analyses. An examination of composited data over an 11-yr period does support such a distinction. Multidimensional scaling (MDS) analyses clearly delineate different assemblages. We suggest that MDS analyses are sensitive to the community differences present near the outfall. The ZID community is clearly contained within the Environmental Protection Agency-approved ZID boundary. Because each ZID and far field site supports a diverse and coarsely similar polychaete fauna, no pollution level effects seem to be present.
\end{abstract}

1 This study was supported by the Department of Environmental Services, City and County of Honolulu, Hawai' $\mathrm{i}$, under contract no. C54997. This is Water Resources Research Center contracted paper CP-2002-04. Manuscript accepted 19 February 2002.

2 Department of Zoology.

${ }^{3}$ Water Resources Research Center.

4 University of Hawai'i at Mānoa, 2538 McCarthy Mall, Honolulu, Hawai'i 96822.

${ }^{5}$ Correspondence to J. H. Bailey-Brock.

Pacific Science (2002), vol. 56, no. 4:459-479 (C) 2002 by University of Hawai'i Press All rights reserved
Environmental measurement and monitoring methods have been debated by ecologists for decades. Defining and monitoring indicator species, determining the proportions of nematodes to copepods, monitoring physical parameters such as granulometry and total organic carbon, and calculating species richness and abundances are widely accepted methods in marine pollution research (Pesch et al. 1987, Jones and Kaly 1996, Krassulya 2001). More recently, ecologists have developed benthic indices for comparative pur- 
poses. Benthic fauna are regularly used because they often represent a substantial portion of the biomass or supply much of the food to the more visible and sometimes commercially valuable water column inhabitants. The methods and models chosen for a particular study often depend upon the investigator's knowledge of the local habitat, trained personnel available for field and laboratory work, or government regulations and approved protocols.

The University of Hawai'i Water Resources Research Center began monitoring environmental conditions surrounding the Sand Island Wastewater Outfall in 1986. This study presents a synthesis of data compiled from the Water Resources Research Center's annual reports from 1990 to 2000 when sampling and reporting practices were standardized as presented in Nelson et al. $(1992 a, b, 1994,1995,1996,1997)$ and Swartz et al. (1998, 1999). The program has been designed to examine the abundance of expected polychaete species and other faunal components within the area defined as the zone of initial dilution (ZID) when compared with similar control sites (far field). Polychaetes are particularly useful because of the relative ease of identification, a trophic position that may respond to the organic enrichment produced by the outfall, their ubiquity in Hawaiian sediments, and densities that often approach 100,000 individuals per square meter. The binary sampling design, ZID versus non-ZID, was chosen to provide ready statistical comparison and to develop a reliable characterization of the ZID-associated community in preparation for more regional and gradient-based studies currently under way.

We base our fundamental assessments on one of the most broadly applied models of biological response to organic enrichment used in many studies from North America, northern Europe, Australia, and India: the Pearson-Rosenberg model (Pearson and Rosenberg 1978). In essence, the benthic community composition is measured along a gradient from a source of organic enrichment to areas outside the zone of influence. The model predicts an increase in species richness and evenness of abundance with increasing distance from the input until the usual abundance, evenness, and species richness for indigenous balanced communities are reached. Numerically dominant polychaete species play a major role in shaping benthic communities and are regarded as indicators of environmental quality (Pocklington and Wells 1992). Changes in species richness, diversity, community evenness, and movement within dominance rankings suggest biological responses to environmental changes and may be reason for concern unless the change can be attributed to a known and benign factor. Graded changes may reflect the dynamic nature of benthic assemblages and provide valuable, time-sensitive baseline data. Rapid and/or inexplicable changes may suggest that a closer examination is called for and that continued monitoring is necessary. In addition to community-level analyses, we examine the 10 numerically dominant species that typically represent 70 to $90 \%$ of collected specimens. By characterizing the life histories of these species and the fluctuations in their abundance from 1990 to the present we hope to gain a better understanding of these benthic assemblages and assess the impacts of organic enrichment by comparing sites within the ZID boundary with those outside it.

Recognizing a species as a "pollution indicator" can have several meanings. Various species have been labeled as indicators for reasons not necessarily consistent among impact studies (Jones and Kaly 1996). Every region is likely to present a different series of positive and negative organic enrichment indicators. Positive indicators may be ecological opportunists whose feeding style, reproduction, and growth allow the population to increase concomitantly with organic input over a relatively short period of time (Davis 1987, Bailey-Brock 1996). Negative indicators are those sensitive species that die directly as a result of conditions related to habitat alteration or are excluded by competitive interactions within the altered habitat.

When comparing invertebrate assemblages between any two sites, within the context of the Pearson-Rosenberg model, it is important to consider influences besides organic en- 


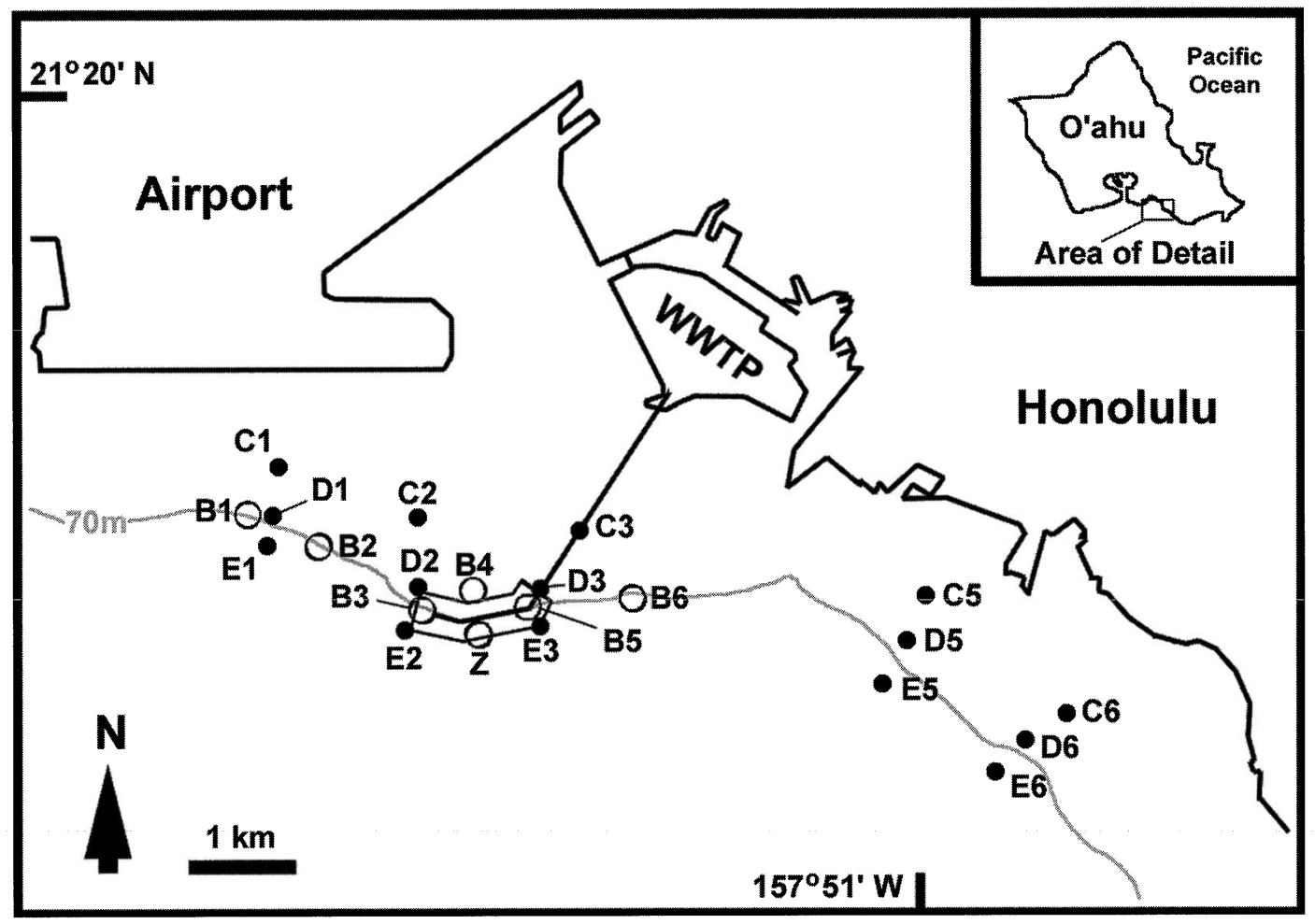

Figure 1. Study area and sample sites in relation to the $\mathrm{O}^{\text {' }} \mathrm{ahu}$ shoreline and $70-\mathrm{m}$ isobath. Open circles denote $70 \mathrm{~m}$ sites sampled from 1990 to 1998 . Solid circles indicate 1999 and 2000 study sites at $20 \mathrm{~m}$ (C), $50 \mathrm{~m}$ (D), and $100 \mathrm{~m}$ (E) depths. WWTP, Sand Island Wastewater Treatment Plant. The border surrounding the outfall's seaward end marks the ZID boundary.

richment that can vary between sites. For benthic polychaetes, many of which are microscopic, the sediment grain size distribution is one such important consideration because space between the grains defines the physical nature of the habitat. The physical composition of sediments broadly affects the available habitat microtopography, oxygen and waste exchange, building material availability, and interstitial stability. Each species' motility and feeding methods may be more or less successful within any particular granulometric environment. Field observations of these animals are extremely difficult to obtain, so our assumptions of motility and feeding methods are based in part on generalizations made by Fauchald and Jumars (1979), deductions based on morphology, and our brief observations of live animals in the laboratory.

\section{MATERIALS AND METHODS}

\section{Sampling Sites and Collection Procedures}

The Sand Island Wastewater Treatment Plant on the south shore of $\mathrm{O}^{\prime}$ ahu, Hawai'i, discharges 60-78 million gallons per day $\left(2.6-3.4 \mathrm{~m}^{3} / \mathrm{sec}\right)$ of primary-treatment effluent at a depth of $70 \mathrm{~m}$ over a sandy bottom. Seven stations at approximately $70 \mathrm{~m}$ depth, four around the diffuser within the ZID, and three approximately $1,1.5$, and $2 \mathrm{~km}$ distant were monitored from 1986 to 1998 (e.g., Nelson et al. 1994). Since then 15 sites at approximately 20,50 , and $100 \mathrm{~m}$ depths were used instead (Swartz et al. 2001) to establish the benthic community composition surrounding the $70-\mathrm{m}$ contour (Figure 1 ).

A single sediment core, $7.6 \mathrm{~cm}$ in diameter and minimally $5 \mathrm{~cm}$ deep, was taken from one 
deployment of a modified $0.16-\mathrm{m}^{2}$ van Veen grab fitted with top-closing flaps. The core was fixed in $10 \%$ buffered formalin, processed to extract the fauna over a $0.5-\mathrm{mm}$ sieve (Nelson et al. 1994), and preserved in $70 \%$ ethanol in water. Six replicate grabs were obtained in the historical study (1990-1998), and three replicates were obtained in the 1999 and 2000 collections. Polychaetes were identified and enumerated. Replicated sediment samples from each station were processed by a dry-sieve method for grain size analyses (Nelson et al. 1994). Chemical parameters of sediments were determined by U.S. Environmental Protection Agencyapproved methods conducted by the City and County of Honolulu and various contract agencies as reported in Nelson et al. (1992a,b, 1994, 1995, 1996, 1997) and Swartz et al. (1998, 1999).

\section{Statistical Analyses}

Diversity was considered using the ShannonWiener statistic $\left(H^{\prime}\right)$ and Pielou's evenness of abundance across species (7). The $H^{\prime}$ statistic is often cited without cautioning the reader that it assumes that all species are present in each sample. This is a serious drawback for our polychaete community analyses because a large percentage of enumerated species belong to only a few taxa throughout the study locale even in "healthy" far field stations. Pielou's evenness takes on a value of -99 when all individuals in a sample belong to one species and a value of +1 when each taxon contributes one individual to the sample. The $K$-dominance curves, diversity $\left(H^{\prime}\right)$ and evenness ( 7 ) statistics, and multidimensional scaling (MDS) analyses were calculated using Plymouth Software's Primer Version 4 (Carr 1997). $K$-dominance curves (Lambshead et al. 1983) have historically been used to help differentiate between communities dominated by one or a few species as illustrated by different curve profiles.

Minitab for Windows Release 12.1 (Minitab, Inc.) was used for tests of significance at the confidence intervals specified, and for linear regression and correlation analyses. Station data for any given year were found to be homoscedastic. Normal distribution was assumed when random observations of abundance, species richness, and derived variables $\left(H^{\prime}\right.$ and 7 ) were analyzed with Minitab.

MDS analyses are increasingly used to directly consider benthic communities with few, if any, assumptions about the data. Krassulya's (2001) comparison of statistical methods useful for investigating organically enriched invertebrate communities strongly supports MDS analyses as the most sensitive method of identifying community differences. Techniques such as $K$-dominance curves and comparisons of richness, abundance, and diversity as used here are robust techniques, but may only detect distinctions at extreme pollution levels. In any monitoring program it is desirable to constantly characterize the impacted areas and provide timely information about changes toward a polluted condition rather than simply affirm whether or not a drastic result has occurred.

Primer's Anosim subroutine was used to compare MDS groupings in one-way and two-way nested tests. Because of software limitations, the 1990-1998 historical data set was split in half to produce one MDS ordination for 1990-1993 data and another for 1994-1998 data. Species contributing less than $5 \%$ of total collected polychaetes were removed from both data sets. Samples were removed randomly to accommodate matrix limits of the software. Ultimately, 61 polychaete species (of 208 observed) among 120 of the 1990-1993 samples (168 total) and 120 samples from 1994-1998 (210 total) were considered in these analyses. All polychaete taxa were included in diversity, evenness, and richness values. Similarity matrices were constructed using the software defaults of Bray-Curtis similarity index, and fourth root transformation of abundance. Graphically representing the three-dimensional similarity array in two dimensions is an iterative process. Primer was therefore instructed to perform 90 random starts, of which the most accurate representation (least stress) is depicted. $K$-dominance and MDS analyses were conducted on both raw numerical abundance and percentage abundance within samples. Because random data reduction was required, 
the nonparametric analyses were performed three times. Results from raw data, percentage values, and repeated randomizations were nearly identical. All abundance data presented here are in terms of percentage abundance within a single sample unless otherwise stated.

\section{Indicator Species}

Dorvilleidae

Ophryotrocha adberens Paavo, Bailey-Brock \& Åkesson, 2000

These are minute (1.2 $\mathrm{mm}$ long) jawed dorvilleids composed of 17-20 segments. Each segment has a prominent ciliary band that aids in locomotion. This species superficially resembles the juveniles of other dorvilleid genera. The prostomium has a single pair of eyes, chemosensory organs, and multiple prostomial glands. The jaw denticles are protrusible and serrated at the tips and are used to scrape organic debris from the substratum. Large mandibles also play a role in defense, mating, and brood care. Laboratory cultures show that $O$. adherens can create water currents with its cilia, allowing it to facultatively filter feed (Paavo et al. 2000).

LIFE History. Opbryotrocha adberens is a protandric simultaneous hermaphrodite, as detailed by Paavo et al. (2000). There is courtship behavior before mating when a functional male attaches to a female. The female constructs a mucus cocoon integrating fecal material and detritus. The time between egg deposition in the cocoons to the first spawning is $18-26$ days at $34^{\circ} \mathrm{C}$. A brief larval period ensures that enough young recruit to and remain near the parent population to add to the immediate local abundance. Individuals can produce several broods of approximately 60 eggs over their typically 20 -week life span. High abundances can be attained over a few weeks.

\section{Nereididae}

Neanthes arenaceodentata (Moore, 1903)

These are some of the largest worms (5-12 $\mathrm{mm}$ long) found in sandy sediments near the outfalls. Adults have 29-54 segments and well-developed parapodia typical of active, motile polychaetes. The head bears two pairs of eyes, a pair of palps, and an eversible muscular pharynx with jaws for grasping food and numerous conical teeth that aid ingestion. Neanthes arenaceodentata is an omnivore that feeds on particles and debris of various sizes. The jaws also play a role in courtship and aggression (Reish 1957).

LIFE HISTORY. Neanthes arenaceodentata has been cultured in laboratory aquariums and used as bioassay organisms (Reish 1957, 1973). Paired worms produce exclusively benthic juveniles after 100 days (first spawning) that remain within the parent population. An omnivorous feeding mode that can directly (scavenging) or indirectly (predation) utilize sediment organics, brood protection, absence of a pelagic larval stage, and active behavior are traits that make this a successful species in food-rich sediments.

Experiments by Pesch et al. (1987) suggested that $N$. arenaceodentata is sensitive to intraspecific density as expressed in the size of paired mature females and their time to first spawning. Those authors appropriately cautioned assayists to consider intraspecific density in subacutely contaminated sediments. Pesch et al.'s highest experimental density was 486 individuals per square meter, whereas Hawaiian field densities of $N$. arenaceodentata were up to 30,000 individuals per square meter, with 7,054 individuals per square meter being median over several years. In contrast to measurements for laboratory-cultured specimens, our largest field specimens $(+20$ $\mathrm{mm}, 68$ setigers) were typically from samples with higher densities. This may indicate that large specimens in low densities are undersampled by our methods. It could also mean that the effects of density in our field conditions are strongly mitigated by environmental conditions near the outfall. Clearly, more work needs to be done at higher densities under various organic enrichment levels for bioassays to accurately detect sediment conditions that are not acutely polluted.

\section{Capitellidae \\ Capitella capitata (Fabricius, 1780)}

Although different microscopic morphologies (such as setiger on which copulatory 
setae appear) can be discerned in the laboratory, C. capitata and Capitella sp. A respond similarly in the environment and are collectively referred to here as the $C$. capitata complex. These are small worms (approximately 2-3 mm long) with reduced head structures and parapodia well adapted for burrowing. The jawless, protrusible proboscis engulfs sediment while burrowing. Capitella capitata is easily maintained in the laboratory in sediments with a high organic content. When present to the exclusion of other species it is considered a common indicator of excessive organic enrichment.

LIFE HISTORY. Capitella capitata males have spines used in mating, and females deposit fertilized eggs into a secreted mucus tube. Pelagic larvae may disperse to other locations or settle nearby. Adults and larvae are often used in bioassay experiments because of their association with sewage outfalls and tolerance of excessive organic enrichment.

Syllidae

Pionosyllis beterocirrata (Hartmann-Schröder, 1959)

These are small $(2-3.5 \mathrm{~mm})$ worms with three pairs of eyes; long, smooth antennae; an armed pharynx; a pair of palps; and welldeveloped parapodia. These active worms have muscular pharynges and appear to feed as detrital omnivores. This is one of the most abundant and widespread polychaete species around $\mathrm{O}^{\prime} \mathrm{ahu}$, regularly representing 5 to $10 \%$ of all enumerated polychaetes at the ocean outfall.

LIFE HISTORY. Syllids may reproduce asexually by budding or sexually by several mechanisms. Pionosyllis beterocirrata has produced young in our laboratory within 3 weeks. Adults have been found with attached embryos that break off and grow as new recruits to the parent population. Eggs are often visible through the body wall. Larvae may disperse to new areas by a brief swimming period (Bailey-Brock 1996). Small size, frequent reproduction by sexual and asexual means, and a relatively short generation time lead to large numbers of $P$. beterocirrata in offshore sandy habitats. This study and work in other sandy O'ahu sediments (BaileyBrock 1996, McCarthy 1996; J.H.B.-B., unpubl. data) suggest that the abundance of $P$. beterocirrata is largely unaffected by the input of organics.

\section{Sabellidae}

Euchone sp. B and Augeneriella dubia Hartmann-Schröder, 1965

Both species are small, tubicolous worms bearing a crown of branching radioles. Specimens of Euchone sp. B are typically $1.5 \mathrm{~mm}$ long, and $A$. dubia is usually twice as large. Sabellids are suspension feeders that use the ciliary surfaces of their crowns to trap and convey small particles to the mouth. They also sweep the sediment surface to collect appropriately sized particles. Grains within a particular size class are ingested, and larger grains may be incorporated into the tube as the worm grows or simply rejected.

Life History. Euchone sp. B and $A$. dubia may reproduce asexually by division within their tubes or sexually by producing pelagic larvae. Sabellids present an array of reproductive strategies from broadcast spawning to intratubular brooding. We have not observed reproductive traits in these species.

\section{RESULTS}

\section{Granulometry and Geochemical Findings}

Time and replicate averaged granulometric analyses (Figure 2) showed a larger component of fine grains ( $\Phi 4$ and finer) present at two far field sites (B1 and B2) compared with all other $70 \mathrm{~m}$ sites. Annual data show a significantly increasing proportion of particles $\Phi$ 4 and finer at stations B1 and B2 throughout the 1990-1998 study period (Table 1). The rate of increase of fine sediments at station B2 was approximately twice that of station B1. The few data points available from 19992000 data at sites D1 and D2 (50 m deep) continued this trend. Stations B3, B4, B5, Z, and B6 did not show any significant grain distribution trends, though annually averaged data of $\Phi 4$ and finer grains at B4 suggest a slow accumulation. Averaged grain size distributions were uniform with medium and 

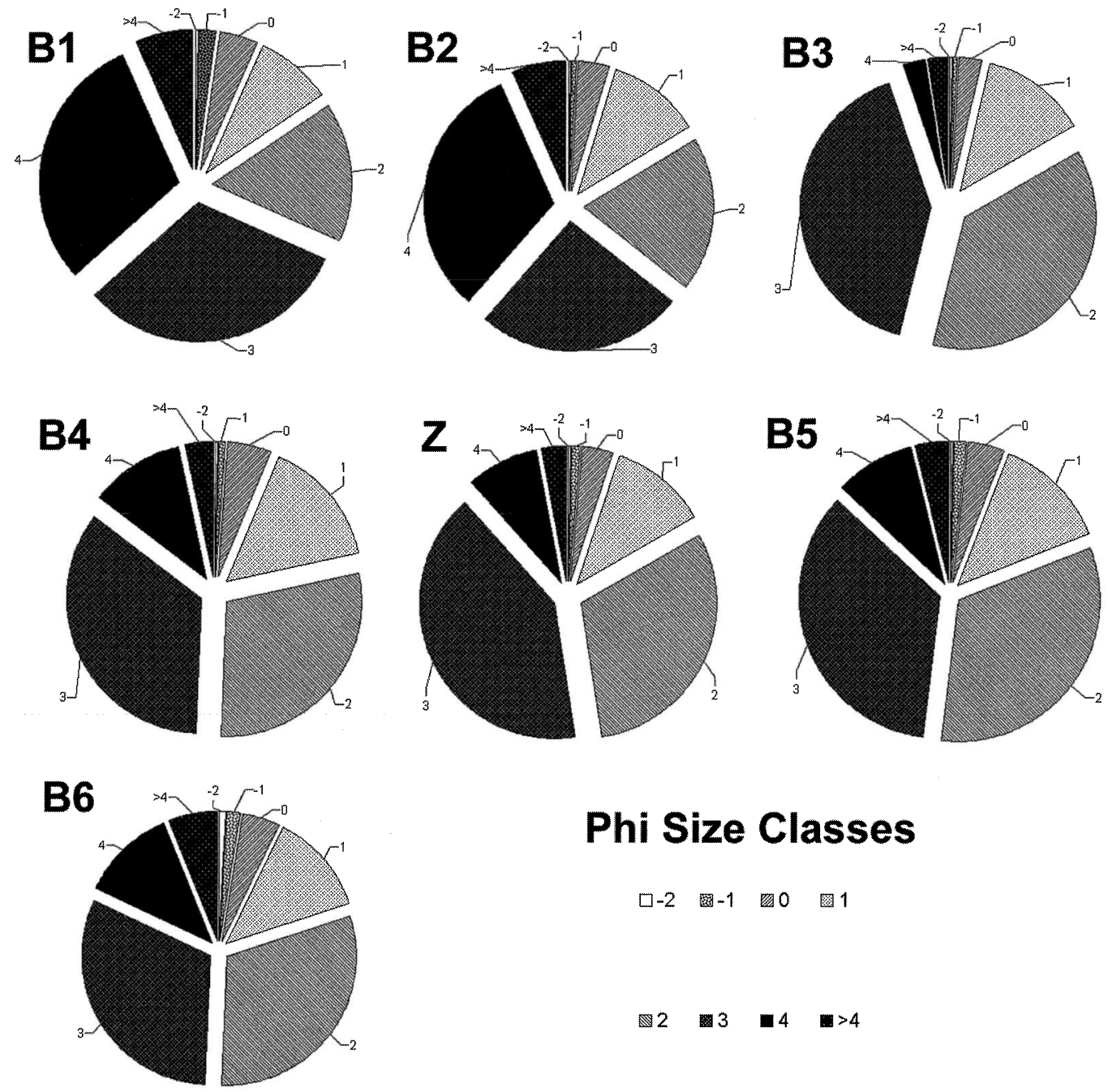

\section{Phi Size Classes}

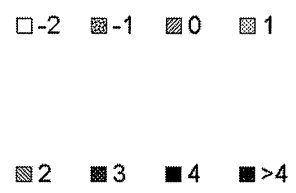

Figure 2. Grain size distributions as averaged over $9 \mathrm{yr}$ from $70 \mathrm{~m}$ historical samples including far field stations (B1, B2, B6) and ZID stations (B3, B4, B5, Z).

coarse fractions in similar proportions at ZID stations B3, Z, B4, B5, and far field station B6.

Geochemical statistical results are summarized in Table 1 . The total organic carbon (TOC) content of sediments ranged from 0.01 to $0.94 \%$ of dry sediment weight, with most measurements lying within the 0.02 to $0.3 \%$ range. Replicates within any station often varied by a factor of two to four. In 1992, TOC levels presented a wider range of values ( 0.01 to $0.95 \%$ dry wt.) spread uniformly among all stations. Overall, there was no significant difference in the measured TOC content of sediments from ZID sites when compared with those of far field sites in a two-sample $t$ test (95\% C.I., $t=-0.10$, $\mathrm{df}=127, \quad P=0.92)$. Regression analysis found a slight significantly increasing trend in TOC levels at all study sites. Total Kjeldahl nitrogen (TKN) as a general nutrient indicator did not differ significantly between ZID 
TABLE 1

Geochemical Statistics of 1990-1998 Study Sites

\begin{tabular}{|c|c|c|c|c|c|c|c|}
\hline \multirow[b]{2}{*}{ Parameter $^{a}$} & \multicolumn{3}{|c|}{ Linear Regression } & \multirow[b]{2}{*}{$n$} & \multirow[b]{2}{*}{ Range } & \multirow[b]{2}{*}{ Mean } & \multirow[b]{2}{*}{ SE Mear } \\
\hline & Equation & $r^{2}$ & $P$ & & & & \\
\hline TOC (ZID) & $\mathrm{TOC}=0.325-0.0364 x$ & $29.7 \%$ & 0.000 & 76 & $0.01-0.94$ & 0.136 & 0.0203 \\
\hline TOC (Non-ZID) & $\mathrm{TOC}=0.265-0.0261 x$ & $16.0 \%$ & 0.000 & 81 & $0.01-0.88$ & 0.135 & 0.0189 \\
\hline TKN (ZID) & $\mathrm{TKN}=305-18.2 x$ & $51.3 \%$ & 0.000 & 76 & $28-523$ & 210.70 & 7.72 \\
\hline TKN (Non-ZID) & $\mathrm{TKN}=261-13.3 x$ & $39.8 \%$ & 0.000 & 79 & $66-296$ & 195.06 & 6.23 \\
\hline ORP (ZID) & $\mathrm{ORP}=34.8+18.4 x$ & $45.9 \%$ & 0.000 & 91 & $22-280$ & 132.47 & 7.05 \\
\hline ORP (Non-ZID) & $\mathrm{ORP}=37.7+11.9 x$ & $22.5 \%$ & 0.000 & 90 & $3-260$ & 97.01 & 6.85 \\
\hline B1 grains $\Phi \geq 4$ & $\% \geq 4=31.6+0.997 x$ & $36.0 \%$ & 0.001 & 27 & $27.3-46.5$ & 36.55 & 0.842 \\
\hline B2 grains $\Phi \geq 4$ & $\% \geq 4=28.9+1.84 x$ & $36.8 \%$ & 0.000 & 29 & $17.9-55.9$ & 38.34 & 1.46 \\
\hline
\end{tabular}

${ }^{a}$ TOC, total organic carbon (\% dry weight); TKN, total Kjeldahl nitrogen (mg N per wet kg sediment); ORP, oxidation-reduction potential $(+\mathrm{mV})$; B1 and B2 grain fraction $\Phi \geq 4$ ( $\%$ total dry weight).

and far field sites in a two-sample $t$ test $(95 \%$ C.I., $t=1.32, \mathrm{df}=126, P=0.19)$. TKN showed a significantly decreasing trend at all study sites over the 1990-1998 period. A two-sample $t$ test indicated that ZID sites produced significantly higher oxidationreduction potential (ORP) values than nonZID sites (95\% C.I., $t=3.37, \mathrm{df}=169$, $P=0.0005)$. Twenty percent of all ORP measurements fell below $50 \mathrm{mV} ; 12 \%$ at far field stations. With the observed variability between replicate measurements, it appears that aerobic conditions were maintained in superficial sediments throughout the study period at all sites. Regression analysis did not find a significant rise or fall of oil and grease levels over the course of the study period. A two-sample $t$ test did not indicate a significant difference in oil and grease levels between ZID and far field sites (95\% C.I., $t=-0.50$, $\mathrm{df}=145, P=0.61)$. Oil and grease levels were routinely between 8 and $500 \mathrm{mg} / \mathrm{kg}$ of wet sediment except during 1992 when all samples ranged between 700 and $1400 \mathrm{mg} / \mathrm{kg}$ in similar site rankings.

\section{Numerical Dominance Relative to the Outfall}

Historical $70 \mathrm{~m}$ results show that Opbryotrocha adberens and Euchone sp. B had antithetical ZID/non-ZID distributions (Figures 3 and 4). Opbryotrocha adberens consistently and abundantly occupied ZID stations B3, B4, Z, and B5; Euchone sp. B specimens were rare at those sites, but numerous at the far field sites B1, B2, and B6. Stations B1 and B2 were distinct in having a much larger proportion of fine grains (Figure 2). Euchone sp. $\mathrm{B}$ abundance, as a percentage of polychaetes sampled, positively and significantly correlated with the increasing proportion of fine grains ( $\Phi 4$ and finer combined) at B2 over. the 1990-1998 study period (correlation = $0.876, P=0.002)$. A nonsignificant but direct correlation was present at stations B1, B4, and B6. Euchone sp. B typically composed 20$50 \%$ of all polychaetes collected at those sites in a given year. Although there were fewer 1999-2000 data, they appear similar. Euchone sp. B was more abundant at the $50 \mathrm{~m}$ sites, the depth most comparable with the historical $70 \mathrm{~m}$ data. Euchone sp. B abundance was depressed at the ZID sites where $O$. adberens was more abundant.

Neanthes arenaceodentata was numerically dominant at ZID site B3 from 1990 to 1992, composing 25 to $70 \%$ of all polychaetes, but was replaced by Opbryotrocha adberens in subsequent years. The general increase in $O$. adherens abundance at ZID stations was matched by a marked decrease in $N$. arenaceodentata over the same period. Neanthes arenaceodentata presents an interesting distribution among the sample sites. Most years produced specimens only from ZID sites. In 1990, 1992, and 1998 non-ZID sites produced very few small individuals, and ZID sites correspondingly produced exceedingly 


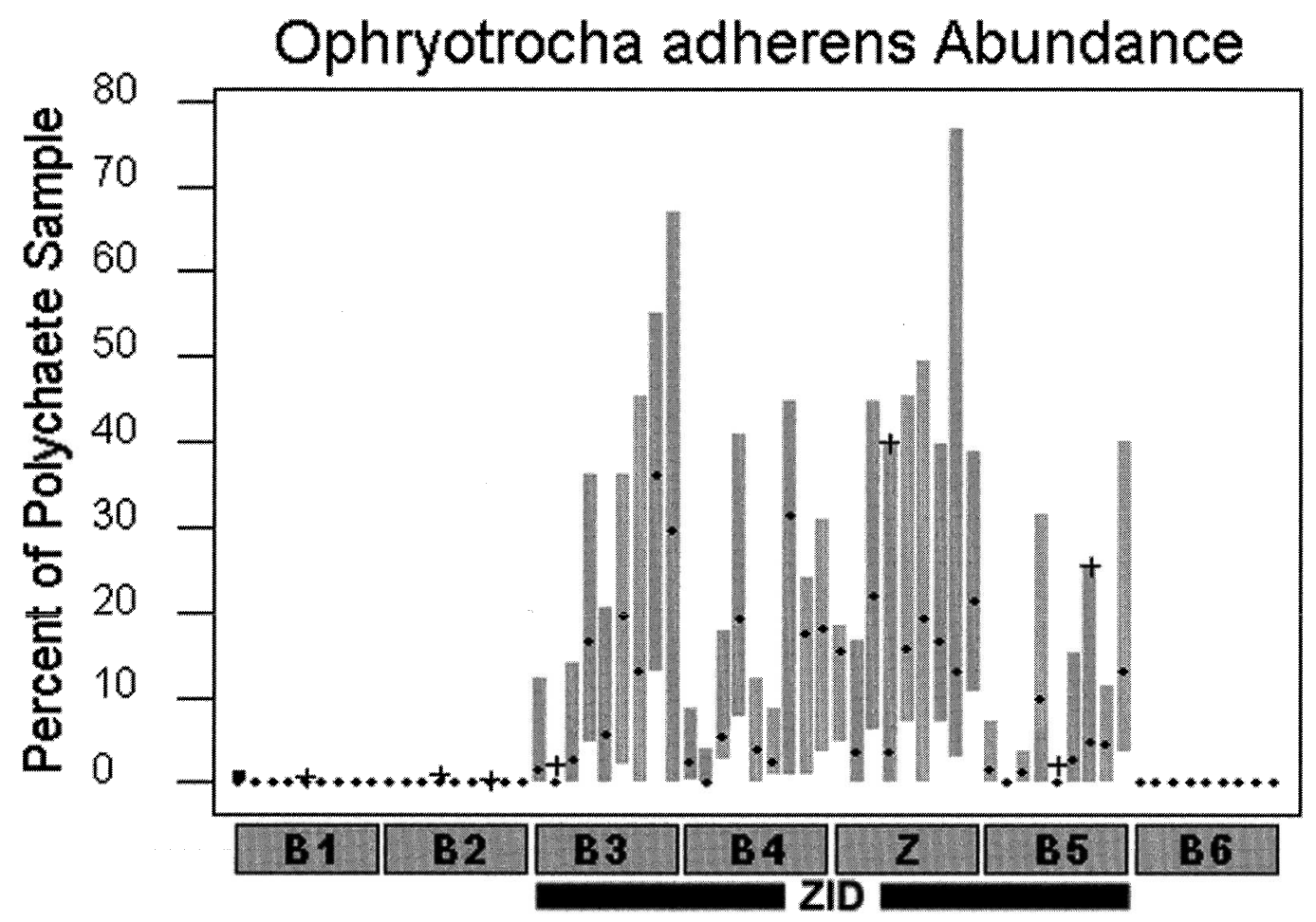

FIGURE 3. Percentage polychaete abundance of Ophryotrocha adberens during $70 \mathrm{~m}$ historical study. Nine columns are present for each station block representing 1990-1998 data from left to right. Vertical bars represent the range; closed circles denote the median; plus signs $(+)$ locate outlying data points from individual replicates.

high numbers and our largest specimens. Abundance of $N$. arenaceodentata at non-ZID stations never exceeded $3 \%$ of collected polychaetes in any given year.

The Capitella capitata complex was consistently present at all $70 \mathrm{~m}$ sites except far field B6 (Figure 5). Capitella abundance fluctuated from year to year, but did so correspondingly at all sites. For example, relatively low abundance was measured at all sites in 1990. In 1992, their proportional abundance approximately doubled at all sites. This increase corresponded to an increase in the measured TOC and oil and grease levels. In 1996, we saw a decrease, again across all sites. The year 1996 presented uniformly low TOC and oil and grease levels. In each of the 10 years studied, Capitella composed a greater proportion of the polychaete collection at ZID site B3 than at any other site. Collectively, ZID sites did not produce a significantly higher proportion of Capitella than non-ZID sites, but far field stations always produced fewer Capitella individuals than ZID site B3.

The two sabellids, Euchone sp. B and $A u$ generiella dubia, presented different distributions. Euchone sp. B was extremely rare within ZID sites and numerous at far field sites B1, $\mathrm{B} 2$, and B6. In contrast, A. dubia composed $30-50 \%$ of the polychaetes at ZID sites B4 and $Z$ in 1994. The sediment analysis that year correspondingly reported a coarser grain distribution than is typical for B4. Augeneriella dubia commonly represented $2-20 \%$ of the polychaetes collected at ZID station B5. Euchone sp. B was abundant in the fine sediments of sites $\mathrm{B} 1$ and $\mathrm{B} 2$. Both species were present in moderate proportions at the far field B6 and were generally absent at ZID stations (with exceptions as already noted). 


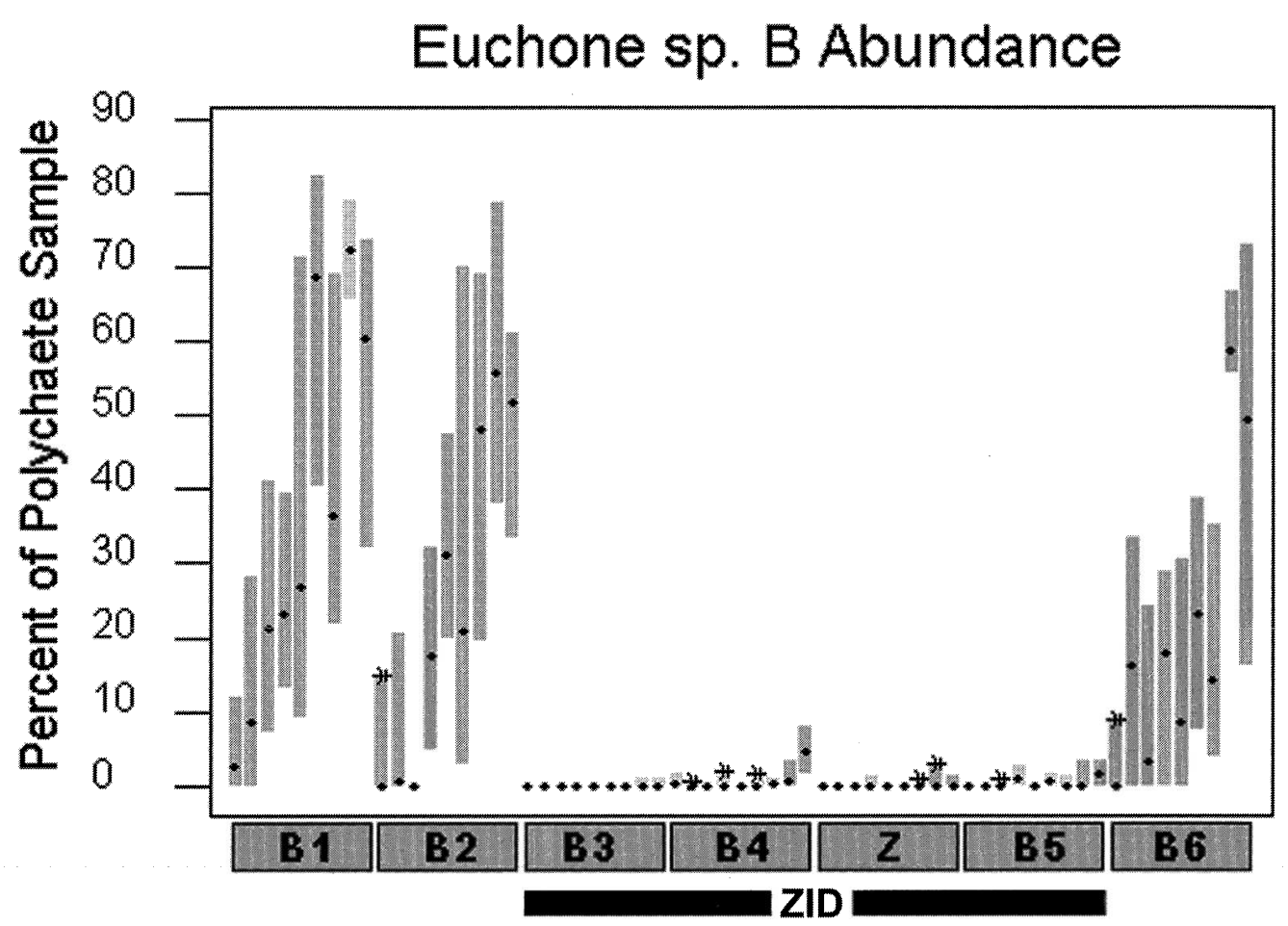

Figure 4. Percentage polychaete abundance of Euchone sp. B during $70 \mathrm{~m}$ historical study. Nine columns are present for each station block representing 1990-1998 data from left to right. Vertical bars represent the range; closed circles denote the median; asterisks $\left(^{*}\right)$ locate outlying data points from individual replicates.

Pionosyllis beterocirrata was a commonly dominant species at all stations in all years. Abundance was stable and typically represented at least $5 \%$ of any given polychaete collection each year. Its numbers appeared depressed at sites B1 and B2 when compared with other $70 \mathrm{~m}$ samples. The 1999 and 2000 data showed it to be well represented at 20-, $50-$, and $100-\mathrm{m}$ isobaths.

Raw polychaete abundances were rarely seen as significantly different between ZID and far field stations in sequential betweenyear tests as reported annually (Swartz et al. 2001). To consider the $70 \mathrm{~m}$ data set as a whole, a two-sample $t$ test was applied to all non-ZID versus an equivalent number (162) of randomly selected ZID samples. ZID samples produced significantly more worms than non-ZID samples (99\% C.I., $P=0.039)$.
Species Richness, Diversity $\left(H^{\prime}\right)$, Evenness ( $\left.\mathcal{7}\right)$, and K-Dominance

When the $70 \mathrm{~m}$ data were considered as 162 observations of ZID versus non-ZID sites, species richness differences were significant. ZID sites produced an average of 18.93 species per sample, and non-ZID sites produced a mean of 22.40 species. This small difference was consistent enough to be significant (99\% C.I., $P=0.0000$ ).

The ZID stations had a significantly higher $H^{\prime}$ value than non-ZID sites $(99 \%$ C.I., $P=0.0000)$. The mean $H^{\prime}$ was 1.989 for non-ZID sites and 2.338 for ZID sites. The ZID samples also presented a more even (mean $\mathcal{F}=0.784$ ) grouping of polychaetes than non-ZID samples (mean $\mathcal{F}=0.707$ ), which tested as significant (99\% C.I., $P=$ 0.0001 ). Both of these values should be inter- 


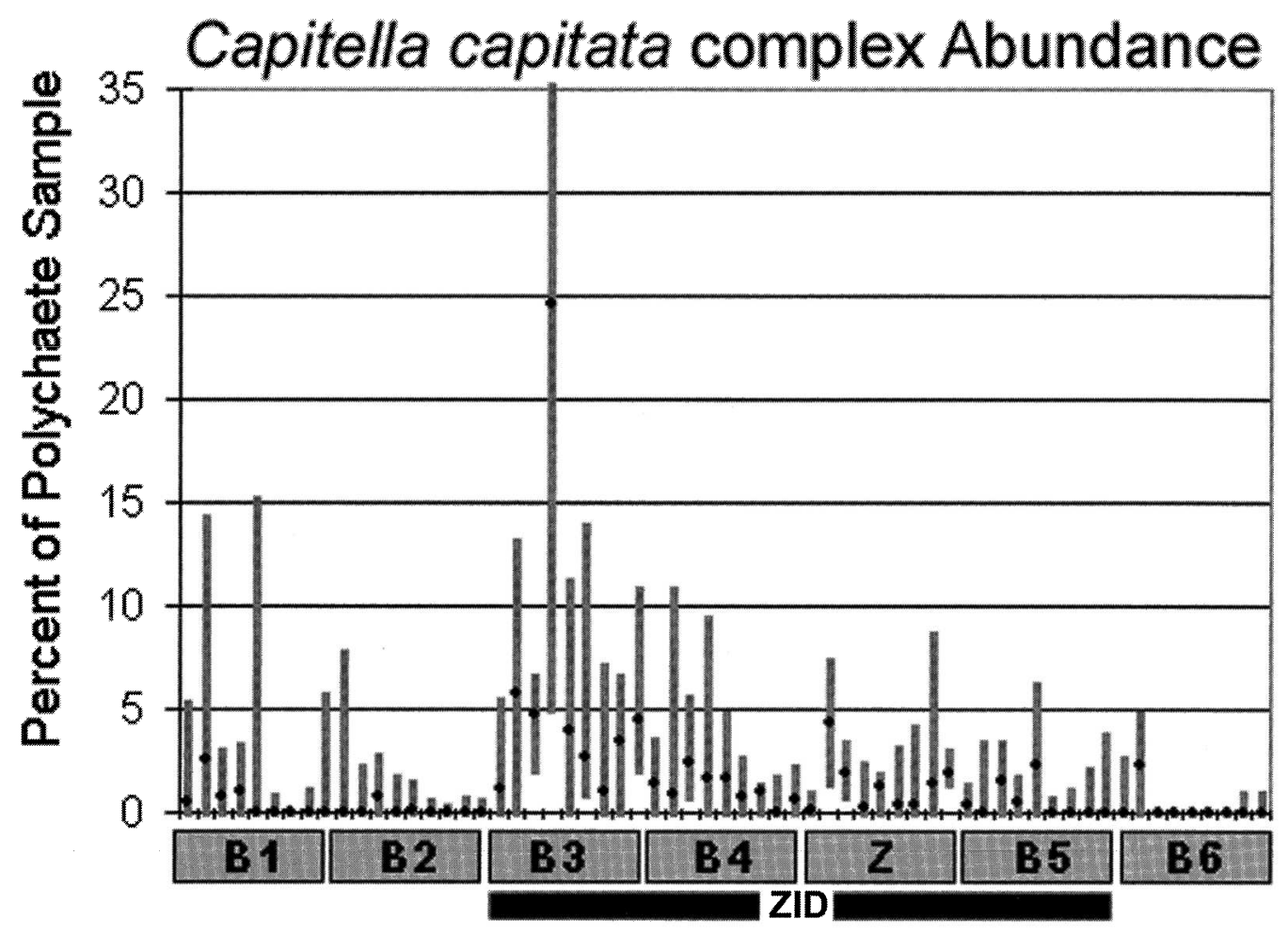

Figure 5. Percentage polychaete abundance of Capitella capitata complex during $70 \mathrm{~m}$ historical study. Nine columns are present for each station block representing 1990-1998 data from left to right. Vertical bars represent the range; closed circles denote the median.

preted with caution because of the inherent limitations of these statistics.

Figure 6 presents the $K$-dominance curves generated from $70 \mathrm{~m}$ data. Although the ZID curve is slightly depressed, both present similar convex profiles, with an intersection far to the right. Similar, nonintersecting shapes denote comparable assemblages amenable to diversity analyses. A polluted site is expected to present a distinctly different (often concave) profile when compared with a presumed unimpacted site presenting a convex curve. Lambshead et al. (1983) have established that intersecting $K$-dominance curves as calculated here indicate that assumptions made by the $H^{\prime}$ and $\mathcal{f}$ statistics have been violated.

\section{MDS Community Analyses}

Anosim analyses were run before viewing MDS ordinations to avoid a priori grouping assumptions. One-way tests comparing ZID versus non-ZID locations strongly supported a distinction with an $R$ value of 0.414 for 1990-1993 data and an $R$ value of 0.627 for 1994-1998 data. An $R$ value of 0.45 corresponds to an unlikely event, with a probability of less than 1 in 1000 if there is no difference between ZID and non-ZID samples. The statistical significance of this type of analysis is necessarily low and can only ever reach $10 \%$ (Clarke and Warwick 1994). Both data sets returned a significance value of $0.0 \%$. Two-way nested Anosim comparisons for distinguishing individual sites (years pooled) produced an $R$ value of 0.426 (significance level $5.7 \%$ ) for $1990-1993$ and an $R$ value of 0.963 (significance level $2.9 \%$ ) for 19941998. These results illustrate each site's independence, but support a distinction between ZID and non-ZID stations.

MDS ordinations for $70 \mathrm{~m}$ from 1990- 


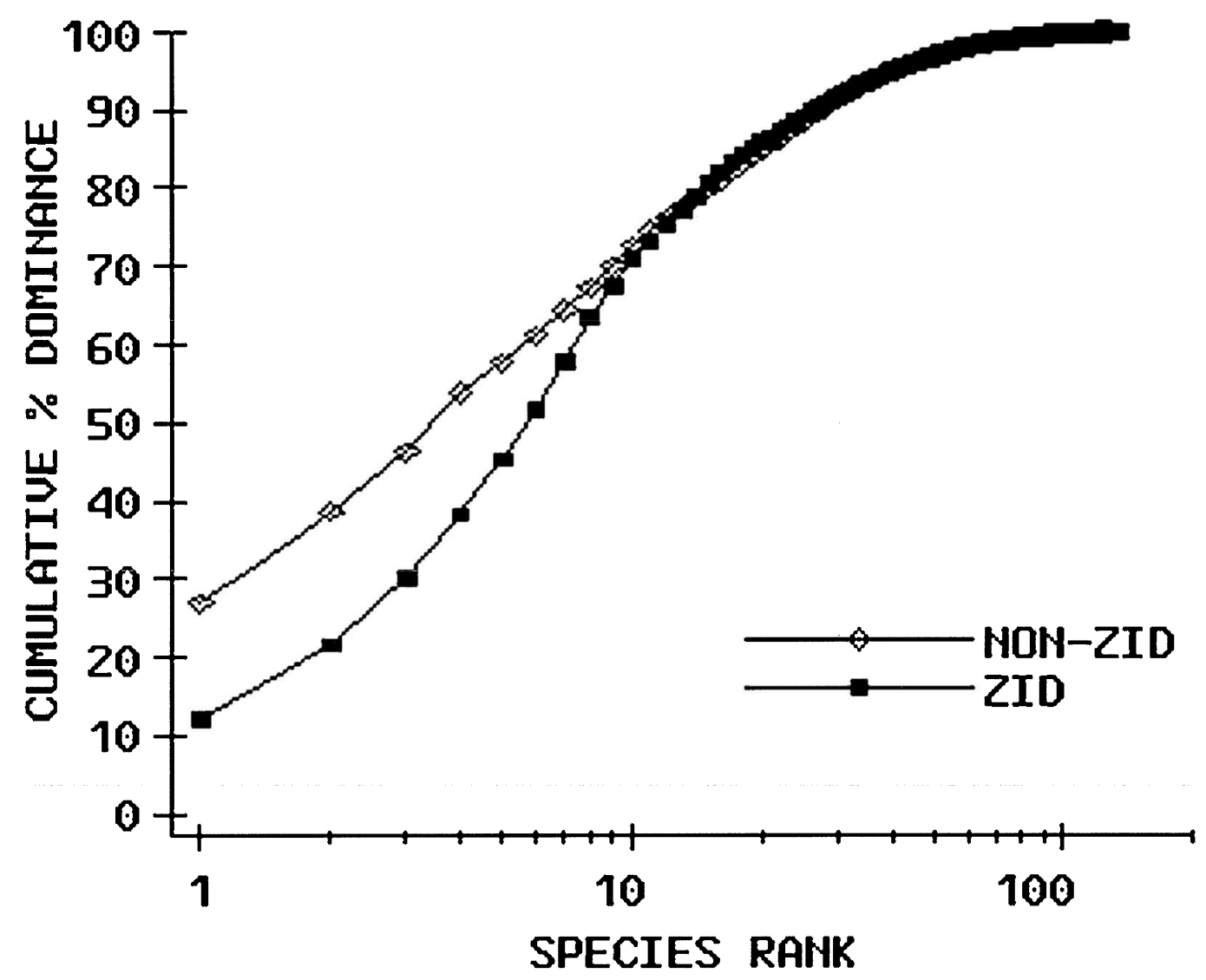

Figure 6. K-dominance curve created with 162 randomly selected samples (92 ZID and 70 non-ZID) from 1990-1998 $70 \mathrm{~m}$ study.

1993 (Figure 7) and from 1994-1998 (Figure 8) clearly show a separation between ZID (Z) and non-ZID $(\mathrm{N})$ samples throughout the study period. When individual stations (years pooled) are labeled, rather than simply nonZID versus ZID samples, groupings within each of the two major clusters indicate the variability of each site (Figures 9 and 10). In 1994-1998 data (Figure 10), stations B1 and B2 appear clustered but highly variable. Samples from B5 and B6 nearly span the ZID/non-ZID condition. Samples from B3, $\mathrm{B} 4$, and $\mathrm{Z}$ define the ZID condition. Comparisons using only the 10 species numerically dominant in the ZID or non-ZID samples during the $70 \mathrm{~m}$ study period produced nearly identical results with a distinct separation between ZID and non-ZID groups.
However, the dispersion of samples within each major group was more diffuse. This led us to the interpretation that our dominant species were the major ordination influences; the presence or absence of rare species provided finer resolution within the major clusters.

Samples collected during the 1999 and 2000 study period produced only six polychaete species new to the Sand Island Wastewater Outfall monitoring program. Figure 11 presents the MDS ordination of the 45 samples collected in 1999 along three depth transects (site series C1-6, D1-6, and E1-6) as compared with 79 randomly selected ZID samples from the 1990-1998 study. Figure 12 similarly presents the 2000 data with the same historical $70 \mathrm{~m}$ ZIID sam- 


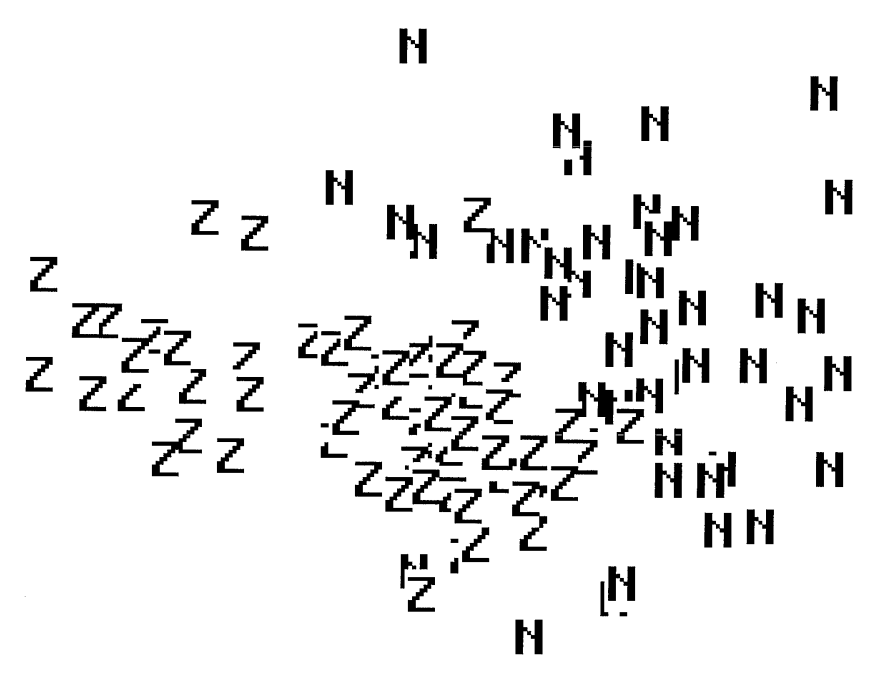

Figure 7. Primer MDS ordination (stress = 0.24) of 1990-1993, $70 \mathrm{~m}$ data. N, non-ZID; Z, ZID.

ples. Five study sites (D2, D3, D5, D6, and E3) clustered within the ZID condition defined by the historical data. Among the 2000 data, only sites D2 and D3 were closely clustered with the historical ZID samples.

\section{DISCUSSION AND CONCLUSIONS}

The Sand Island Wastewater Outfall typically discharges 2.6 to $3.4 \mathrm{~m}^{3} / \mathrm{sec}$ of advanced primary effluent through 285 ports located along nearly $2 \mathrm{~km}$ of diffuser at depths ranging from 67 to $72 \mathrm{~m}$. Although the outfall is obviously releasing nutrients into the environment in the form of dissolved and particulate organic carbon, it does not appear that a measurably substantial amount is deposited as detritus directly available to benthic epi- and infauna. Dollar, as summarized in Nelson et al. $(1992 a, b)$, reported that little $(<1 \%)$, if any, particulate matter ever reaches the sediment surface. Roberts (1996) measured bottom currents in the immediate vicinity of historical site B5 as predominantly westward and typically ranging from 0 to $30 \mathrm{~cm} / \mathrm{sec}$, rarely reaching $50 \mathrm{~cm} / \mathrm{sec}$. The geochemical parameters reported here indicate that very little benthic accumulation of effluent is occurring, likely due to the local water flow regime combined with the effluent's low salinity.

Although organic enrichment is often presumed to be the primary influence on adjacent benthic communities, municipal effluents and the physical structure of outfalls in nutrient-poor tropical waters may present additional confounding factors. Riddle et al. (1990) reported that although there is a pau- 


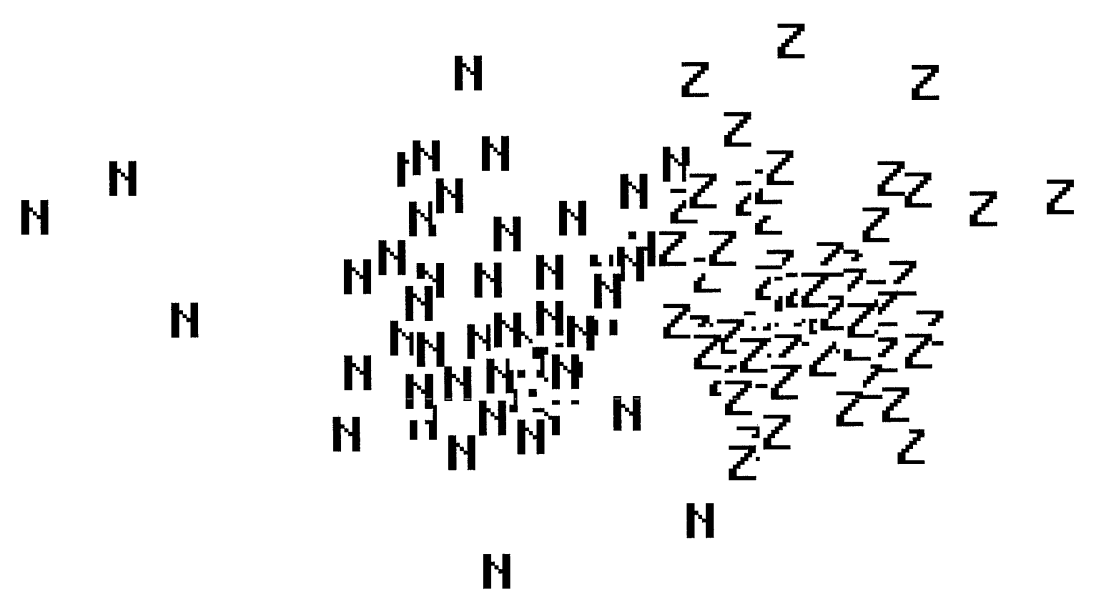

Figure 8. Primer MDS ordination (stress = 0.22) of 1994-1998, $70 \mathrm{~m}$ data. N, non-ZID; Z, ZID.

city of data on benthic productivity in tropical sediments, studies by Ansell and Parulekar found that tropical biomass often had a turnover rate up to 10 times that of temperate systems. The physical structure of the outfall and its capstones acts as an artificial reef that supports a greater standing stock of fish and sessile invertebrates (Brock 2001) than the surrounding sandy environment. Posey and Ambrose (1994) and Davis et al. (1982) demonstrated that fish aggregated by artificial structures or isolated hard substrata have a significant effect on shaping benthic communities within a 75 - to $140-\mathrm{m}$ radius.

Nine years of monitoring efforts at $70 \mathrm{~m}$ identified three polychaetes, Opbryotrocha adberens, Neanthes arenaceodentata, and the Capitella capitata complex, closely associated with sediments immediately surrounding the Sand Island Wastewater Outfall. Neanthes arenaceodentata and the $C$. capitata complex are recognized internationally as pollution indicators. Capitella capitata tolerates higher sediment organic levels, including hydrocarbons, and anaerobic conditions more than most polychaete species, as demonstrated experimentally by Bridges et al. (1994). The decline of $N$. arenaceodentata was one of the most noticeable changes in the benthic community at the Sand Island Wastewater Outfall. It seems unlikely that the smaller worm, $O$. adherens, actively displaced $N$. arenaceodentata at the ZID. Both species have life history traits that favor juvenile recruitment into the parent population, leading to rapid population increase in the immediate vicinity 


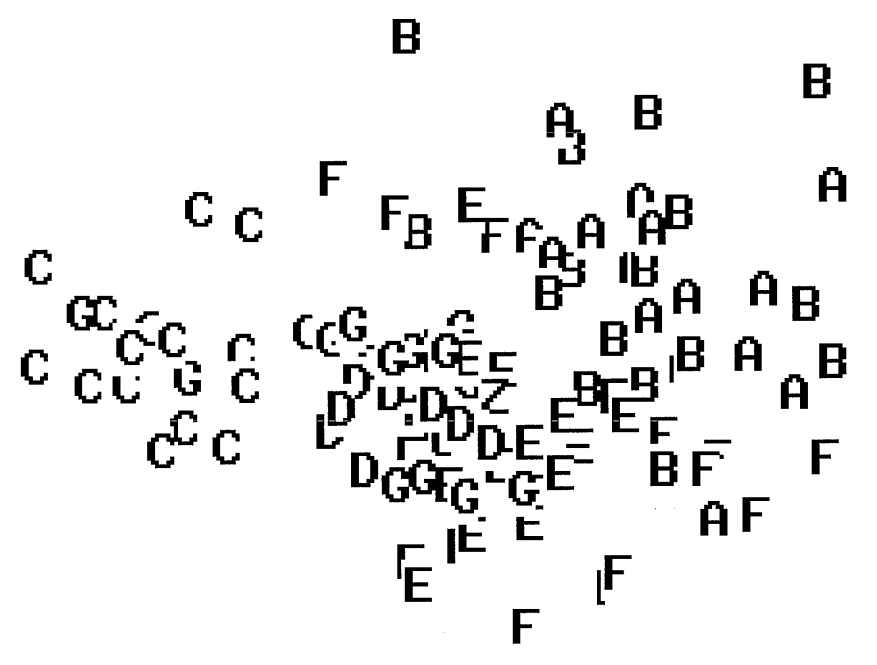

FIGURE 9. MDS identical to Figure 7, but with individual stations indicated. A, B1; B, B2; C, B3; D, B4; E, B5; F, B6; $\mathrm{G}, \mathrm{Z}$.

and reduced dispersal to new locations. An explanation for this change may be that $O$. adberens reproduces faster and reaches higher abundances on a smaller spatial scale (typically 8000 to 20,000 individuals per square meter) than $N$. arenaceodentata. The nereidid life cycle includes a longer generation time, a large size, and a high level of activity, which suggests that this worm may not have been sampled adequately with the 7.6-cm-diameter corer. Both species share the characteristics of an active lifestyle: young that are retained in the parent population close to food resources, and an omnivorous feeding mode. However, the smaller species numerically dominated the ZID benthos. We suggest that $N$. arenaceodentata abundance has dramatically declined from ubiquity to almost complete local extinction due to an unknown cause and the smaller $O$. adherens abundance rose in the absence of $N$. arenaceodentata competition. Three years in which $N$. arenaceodentata was detected outside the ZID corresponded with extremely high ZID abundances. We believe this supports the supposition that conditions surrounding the outfall enhance $N$. arenaceodentata reproduction and that small specimens recorded from the ZID sites represent dispersed young. These young seem to be poor colonists of distant sediments.

The well-known indicator Capitella capitata has been present at the outfall since 1986 and continues to exist in moderate abundance. It has also been found at fish farms using net cage culture in Japan and off $\mathrm{O}^{\prime}$ ahu (Tsutsumi 1987, Tsutsumi et al. 1990, Bybee and 


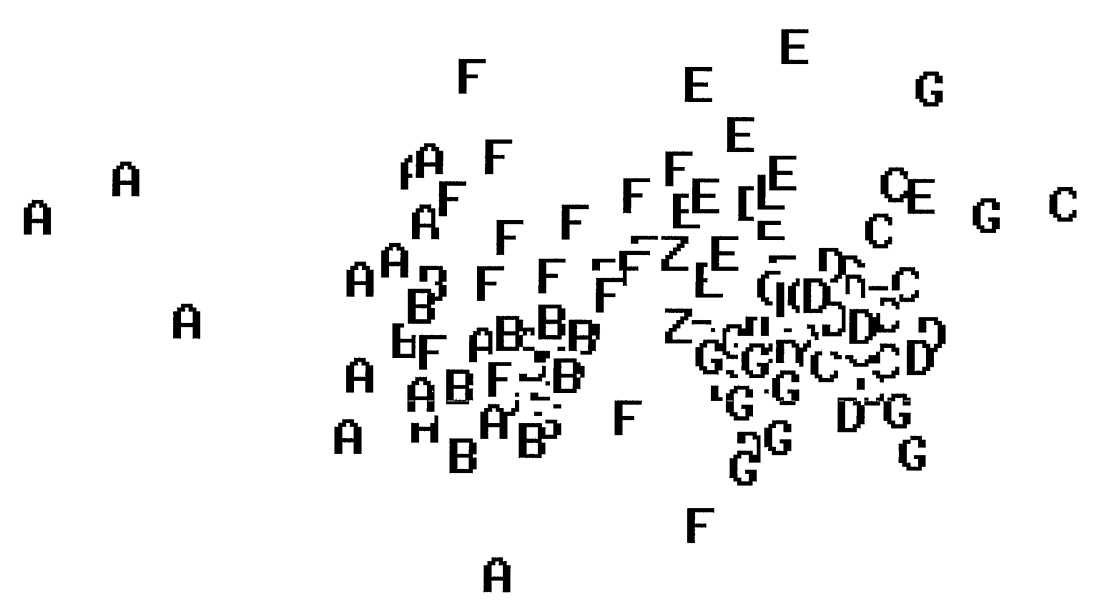

FIGURE 10. MDS identical to Figure 8, but with individual stations indicated. A, B1; B, B2; C, B3; D, B4; E, B5; F, B6; $\mathrm{G}, \mathrm{Z}$.

Bailey-Brock in press), near sewage outfalls (Nelson et al. 1994), and outside the mouth of the eutrophic Ala Wai Canal (McCarthy 1996, McCarthy et al. 2000). The abundance of the C. capitata complex did not appear to be affected by the grain size distributions encountered in this study. These polychaetes were consistently present in higher numbers near the outfall and increased at other stations during periods of elevated TOC and oil and grease levels.

Augeneriella dubia is a ZID-associated species with feeding, reproduction, and life history traits similar to those of Euchone sp. B. The former appears to do particularly well in coarse sands, and the latter thrives in finer sediments. Euchone sp. B is a common inhabitant of control stations, but it has not played an important role in communities immediately adjacent to the outfall. Absence at the ZID points to the lack of suitable habitat for this species.

Pionosyllis beterocirrata has been consistently abundant throughout this study. Other studies (McCarthy 1996, Bybee and BaileyBrock in press) have reported that it has been similarly abundant at other locations around $\mathrm{O}^{6}$ ahu. Any future reduction in abundance or absence at the ZID would be cause for concern, and in-depth monitoring would be advisable. This robust and active species is the most commonly encountered species in coral sands at these depths around $\mathrm{O}^{\prime}$ ahu shores.

Community analyses using abundance and diversity assessments applied to the PearsonRosenberg model will likely detect a large or 


\section{B}

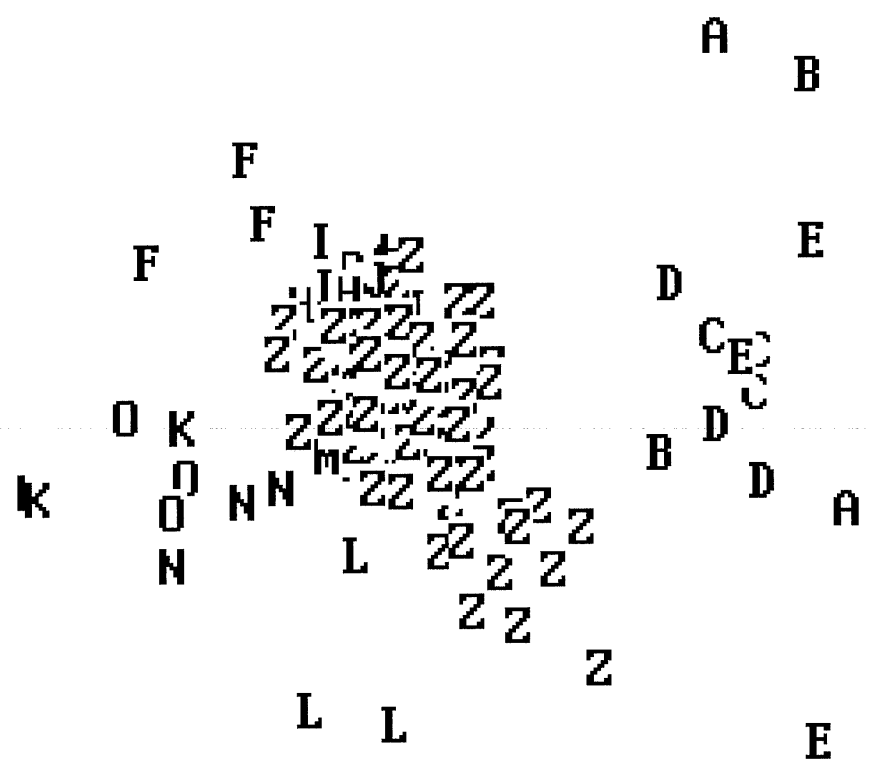

FIGURE 11. Primer MDS ordination (stress $=0.21$ ) of 1999 polychaete data as compared with 75 randomly selected ZID samples from the 1990-1998, $70 \mathrm{~m}$ data. Z, $70 \mathrm{~m}$ ZID; A, C1; B, C2; C, C3; D, C5; E, C6; F, D1; G, D2; H, D3; I, D5; J, D6; K, E1; L, E2; M, E3; N, E5; O, E6.

extremely rapid organic enrichment event. Species richness has been regularly calculated and compared on a between-year and between-station basis during annual reporting. The results were rarely significant. No such pollution destructive to benthic assemblages seems to be present at the Sand Island Wastewater Outfall as determined by this study and by Swartz et al. (2001). Carefully considered species-level comparisons offer finer resolution by examining individual, biologically key components of the benthos adjacent to the outfall. In addition, MDS analyses offer an opportunity to examine the speciose polychaete assemblages as a whole, allowing a more finely resolved picture of the benthic environment. Any future samplings near the outfall should be placed in this historical data matrix to see if they appear more like a historical ZID or non-ZID station. In 


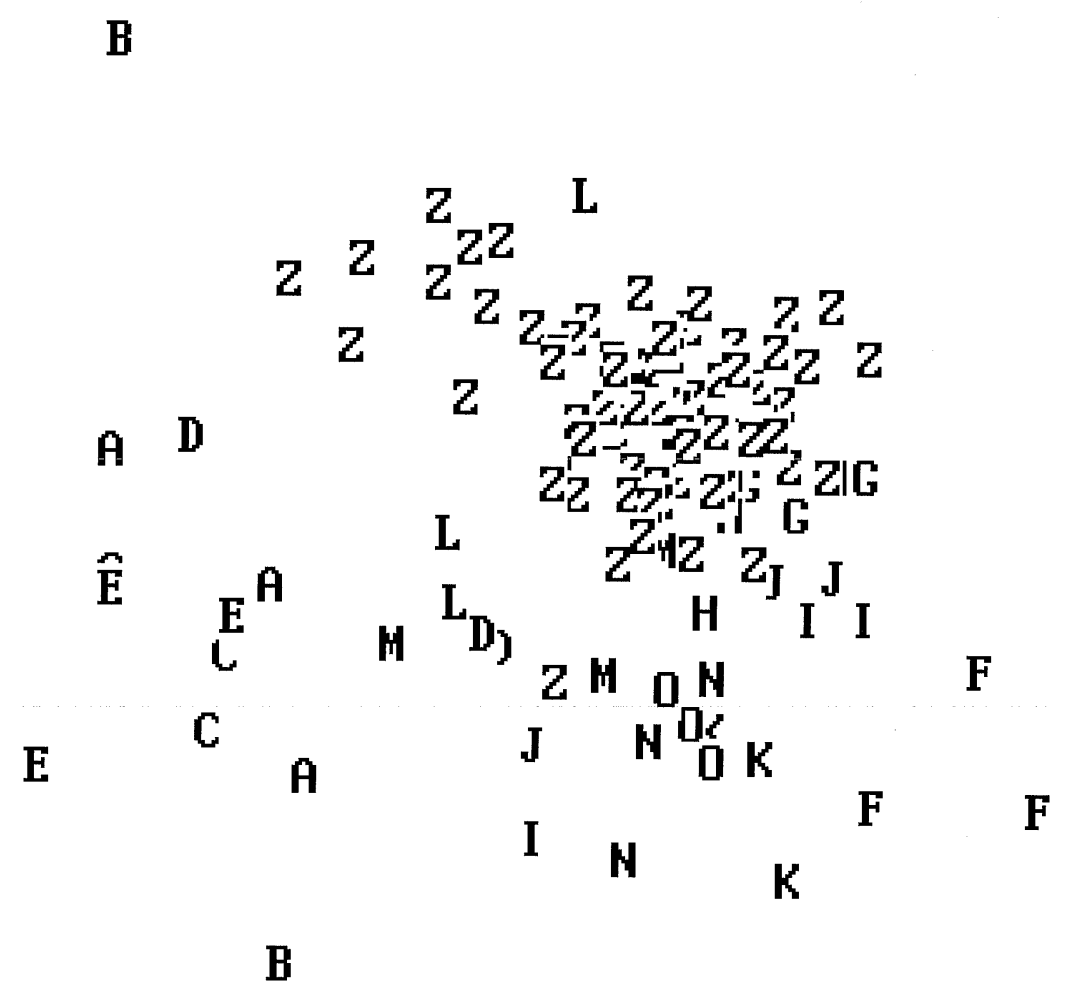

FIgURE 12. Primer MDS ordination (stress $=0.23$ ) of 2000 polychaete data as compared with 75 randomly selected ZID samples from the 1990-1998, $70 \mathrm{~m}$ data. Z, $70 \mathrm{~m}$ ZID; A, C1; B, C2; C, C3; D, C5; E, C6; F, D1; G, D2; H, D3; I, D5; J, D6; K, E1; L, E2; M, E3; N, E5; O, E6.

this fashion the community transition and therefore the current "boundary" of impact might be delineated. It would be instructive to define and compare this "actual impact" boundary with the arbitrarily determined EPA boundary within the context of O'ahu's unique hydrogeographic environment to facilitate locally appropriate management decisions. Recent software developments will ensure that future assessments will be able to simultaneously analyze the full data set without resorting to the data reduction necessitated in this study.

Initial examinations of the 20,50, and 100 $m$ data (this study and Swartz et al. 2001) indicate that depth may be a stronger force in shaping the polychaete communities than proximity to the outfall for stations outside the ZID. Future sampling efforts should consider comparing individual yearly samples 
with historical MDS ordinations to help delineate the outfall's impact and to further examine the diversity of O'ahu's southern shore. Our analysis indicates that conditions adjacent to the outfall positively enhance polychaete abundance and species composition without substantially degrading the habitat. It is likely that any organic enrichment reaching the sediment from the outfall can be converted rapidly to faunal biomass. More detailed studies on the role of organic carbon and its measurement in sandy tropical sediments are required. The accumulation of fine sediment particles at control stations B1 and B2 does not appear to indicate an accumulation of outfall-associated particulates. Any potential enrichment effects appear to be confined to the ZID boundary. Future studies should include multiple factor analysis to further define the effects depth, proximity to the outfall (and other hard substrata), and sedimentary physical parameters have on shaping the benthic communities of the region. The sediment composition, specifically surrounding historic sites B1 and B2, should continue to be monitored with the goal of identifying the source of increasing fine particulates, perhaps utilizing recent advances in stable isotope analyses and carbohydrate measurement techniques. Dominant species monitoring and MDS analyses offer the potential of an "early warning system" of organic enrichment when compared with typical community level analyses in addition to providing fundamental insights into the forces shaping benthic communities and should form a regular part of future monitoring efforts.

\section{ACKNOWLEDGMENTS}

We are grateful to the City and County of Honolulu for funding the biomonitoring program and the Environmental Division for collecting samples and providing grain size analyses. James Moncur (project director), Karen Tanoue (editor), and Philip Moravcik (specialist) at the University of Hawai' $i$ Water Resources Research Center coordinated many components of this research. Our thanks to the University of Hawai'i Zoology
Department and the Wormlab staff for sorting and identifying the $30,000+$ polychaetes collected over the last $15 \mathrm{yr}$ for these data. This report benefited from the insightful comments of two anonymous reviewers.

\section{Literature Cited}

Bailey-Brock, J. H. 1996. Definition of indicator species for pollution monitoring in Māmala Bay, O’ahu, Hawai'i. Māmala Bay Study Final Report. The Māmala Bay Study Commission. Project MB-9, Vol. 2. Water Resources Research Center, University of Hawai'i at Mānoa, Honolulu. Available at WRRC Library.

Bridges, T. S., L. A. Levin, D. Cabrera, and G. Plaia. 1994. Effects of sediment amended with sewage, algae, or hydrocarbons and reproduction in two opportunistic polychaetes. J. Exp. Mar. Biol. Ecol. 177:99-119.

Brock, R. E. 2001. Community structure of fish and macrobenthos at selected shallowwater sites in relation to the Barbers Point Ocean Outfall, 2001. Project Report PR-2002-03. Water Resources Research Center, University of Hawai'i at Mānoa, Honolulu. Available at WRRC Library.

Bybee, D., and J. H. Bailey-Brock. In press. Effect of a Hawaiian open ocean fish culture system on the benthic community. Proceedings, Open Ocean Aquaculture IV Conference, 17-20 June 2001, St. Andrews, New Brunswick. Mississippi-Alabama SeaGrant Consortium.

Carr, M. R. 1997. Primer user manual: Plymouth routines in multivariate ecological research. Plymsolve, Plymouth Marine Laboratory, Prospect Place, The Hoe, Plymouth PL13DH, United Kingdom.

Clarke, K. R., and R. M. Warwick. 1994. Change in marine communities: An approach to statistical analysis and interpretation. Plymouth Marine Laboratory, Plymouth, United Kingdom. Distributed with Primer software.

Davis, D. A. 1987. Analysis of sublittoral benthic habitats of the Sand Island deep ocean sewage outfall: Community structure and indicator organisms. M.S. thesis, 
University of Hawai'i at Mānoa, Honolulu.

Davis, N., G. R. VanBlaricom, and P. K. Dayton. 1982. Man-made structures on marine sediments: Effects on adjacent benthic communities. Mar. Biol. (Berl.) 70:295-303.

Fauchald, K., and P. A. Jumars. 1979. The diet of worms: A study of polychaete feeding guilds. Oceanogr. Mar. Biol. Annu. Rev. 17:193-284.

Hartmann-Schröder, G. 1959. Zur Ökologie der Polychaeten des Mangrove-EsteroGebietes von El Salvador. Beitr. Neotrop. Fauna 1 (2): 70-83.

- 1965. Zur kenntnis der eulitoralen polychaetenfauna von Hawaii, Palmyra und Samoa. Sonderdruck Abh. Verh. Naturwiss. Ver. Hambg, N.F. Bd., Suppl. 9:81-160.

Jones, G. P., and U. Kaly. 1996. Criteria for selecting marine organisms in biomonitoring studies. Pages 29-48 in R. J. Schmitt and C. W. Osenberg, eds. Detecting ecological impacts: Concepts and applications in coastal habitats. Academic Press, San Diego.

Krassulya, N. 2001. Choice of methodology for marine pollution monitoring in intertidal soft-sediment communities. Cent. Biol. Mangfald Skriftser. 3:131-148.

Lambshead, P. J. D., H. M. Platt, and K. M. Shaw. 1983. The detection of differences among assemblages of marine benthic species based on an assessment of dominance and diversity. J. Nat. Hist. 17:859-874.

McCarthy, S. A. 1996. Patterns of spatial and temporal variability in Hawaiian softbottom benthos. Ph.D. diss., University of Hawai'i at Mānoa, Honolulu.

McCarthy, S. A., E. A. Laws, W. A. Estabrooks, J. H. Bailey-Brock, and E. A. Kay. 2000. Intra-annual variability in Hawaiian shallow-water, soft-bottom macrobenthic communities adjacent to a eutrophic estuary. Estuarine Coastal Shelf Sci. 50:245258.

Moore, J. P. 1903. Description of two new species from Woods Hole, Mass. Proc. Acad. Nat. Sci. Phila. 55:720-726.

Nelson, W. G., J. H. Bailey-Brock, W. J.
Cooke, and E. A. Kay. 1992a. Benthic faunal sampling adjacent to Sand Island Ocean Outfall, O'ahu, Hawai'i, August 1991. Project Report 04.20:92. Water Resources Research Center, University of Hawai'i at Mānoa, Honolulu. Available at WRRC Library. 1992b. Benthic faunal sampling adjacent to Sand Island Ocean Outfall, $\mathrm{O}^{6} \mathrm{ahu}$, Hawai'i, August 1992. Project Report 12.08:92. Water Resources Research Center, University of Hawai'i at Mānoa, Honolulu. Available at WRRC Library.

1994. Benthic faunal sampling adjacent to Sand Island Ocean Outfall, O'ahu, Hawai'i, August 1993. Project Report PR94-13. Water Resources Research Center, University of Hawai'i at Mānoa, Honolulu. Available at WRRC Library.

1995. Benthic faunal sampling adjacent to Sand Island Ocean Outfall, O'ahu, Hawai'i, August 1994. Project Report PR95-09. Water Resources Research Center, University of Hawai'i at Mānoa, Honolulu. Available at WRRC Library.

1996. Benthic faunal sampling adjacent to Sand Island Ocean Outfall, $\mathrm{O}^{6} \mathrm{ahu}$, Hawai'i, August 1995. Project Report PR96-07. Water Resources Research Center, University of Hawai'i at Mānoa, Honolulu. Available at WRRC Library.

- 1997. Benthic faunal sampling adjacent to Sand Island Ocean Outfall, O'ahu, Hawai' $i$, September 1996. Project Report PR-97-06. Water Resources Research Center, University of Hawai'i at Mānoa, Honolulu. Available at WRRC Library.

Paavo, B., J. H. Bailey-Brock, and B. Åkesson. 2000. Morphology and life history of Ophryotrocha adberens sp. nov. (Polychaeta, Dorvilleidae). Sarsia 85:251264.

Pearson, T. H., and R. Rosenberg. 1978. Macrobenthic succession in relation to organic enrichment and pollution of the marine environment. Oceanogr. Mar. Biol. Annu. Rev. 16:229-311.

Pesch, C. E., R. N. Zajac, R. B. Whitlatch, and M. A. Balboni. 1987. Effect of intraspecific density on life history traits and population growth rate of Neanthes arena- 
ceodentata (Polychaeta: Nereidae) in the laboratory. Mar. Biol. (Berl.) 96:545-554.

Pocklington, P., and P. G. Wells. 1992. Polychaetes, key taxa for marine environmental quality monitoring. Mar. Pollut. Bull. 24 (12): 593-398.

Posey, M. H., and W. G. Ambrose Jr. 1994. Effects of proximity to an offshore hardbottom reef on infaunal abundances. Mar. Biol. (Berl.) 118:745-753.

Reish, D. J. 1957. The life history of the polychaetous annelid Neanthes caudata (delle Chiaje), including a summary of development in the family Nereidae. Pac. Sci. 11:216-228.

. 1973. The use of benthic animals in monitoring the marine environment. J. Environ. Planning Pollut. Control 1 (3): 32-38.

Riddle, M. J., D. M. Alongi, P. K. Dayton, J. A. Hansen, and D. W. Klumpp. 1990. Detrital pathways in a coral reef lagoon: Macrofaunal biomass and estimates of production. Mar. Biol. (Berl.) 104:109-118.

Roberts, P. J. W. 1996. Plume modeling. Māmala Bay Study Final Report. The Māmala Bay Study Commission. Project MB-4, Vol. 1. Water Resources Research Center, University of Hawai'i at Mānoa, Honolulu. Available at WRRC Library.
Swartz, R. C., J. H. Bailey-Brock, W. J. Cooke, and E. A. Kay. 1998. Benthic faunal sampling adjacent to Sand Island Ocean Outfall, O'ahu, Hawai'i, August 1998. Project Report PR-98-08. Water Resources Research Center, University of Hawai'i at Mānoa, Honolulu. Available at WRRC Library. 1999. Benthic faunal sampling adjacent to Sand Island Ocean Outfall, O'ahu, Hawai'i, August 1998. Project Report PR99-10. Water Resources Research Center, University of Hawai' $i$ at Mānoa, Honolulu. Available at WRRC Library.

- 2001. Macrobenthos monitoring near Sand Island and Barbers Point outfalls, O'ahu, Hawai'i. Pages 1408-1416 in Proceedings, Marine Technology Society/ Institute of Electrical and Electronics Engineers, Oceans 2001: An ocean odyssey.

Tsutsumi, H. 1987. Population dynamics of Capitella capitata (Polychaeta: Capitellidae) in an organically polluted cove. Mar. Ecol. Prog. Ser. 36:139-149.

Tsutsumi, H., S. Fukunaga, N. Fujita, and M. Sumida. 1990. Relationship between growth of Capitella sp. and organic enrichment of the sediment. Mar. Ecol. Prog. Ser. 63:157-162. 